JEL: C55, E37, 011, 013

Viktoriia Dmytriieva $^{1}$, Yurii Sviatets ${ }^{2}$

${ }^{1}$ Dnipro State Agrarian and Economic University

${ }^{2}$ Oles Honchar Dnipro National University

Ukraine

\title{
TURNING POINTS IN AGRICULTURE DEVELOPMENT IN UKRAINE: RESULTS OF ANALYSIS ON THE BASE OF PURIFIED DATA
}

Purpose. The purpose of the paper is to study agriculture development in independent Ukraine using methods for decomposition of data sets to obtain structural components according to their level of determination and to investigate main tendencies without random fluctuation.

Methodology / approach. This research uses econometrics methods of regression and correlation dynamics, data filtering from random factors impact, comparison method to reconstruct trends in agriculture development. The accent is made on the differences between results of analysis on the base of uncleaned and purified data. The cleaning process was made by the HodrickPrescott method for data sets decomposition without loss of information into several functions that describe behavior of system formed under deterministic, periodical, and stochastic influence. The calculations and their visualization were held by means of GNU Octave. The research covered the period of 1996-2018 years in development of agriculture, forestry, and fisheries in Ukraine.

Results. This paper emphasizes on the necessity to clean data before its analysis. Unlike the analysis based on the raw data the reconstruction of relationships between filtered data sets allows building models of agriculture dynamics more precisely. The article presents reconstructed main correlated dynamics that were formed by deterministic impacts in Ukraine agriculture. Besides, the crucial turning points in Ukraine agriculture development were revealed because of analysis of filtered data. It is shown how data cleaning raises analysis quality.

Originality / scientific novelty. Reconstruction of economy regression models on the dynamic data sets can be followed by the risks of wrong interpretation of results. To have correct explanation of regularity it matters to eliminate from data sets the fluctuations formed by random impacts and to study relation of tendencies in connection with structural shifts in the development of the country. The advisability and the necessity to use such approaches are proved by this research that was held on the base of statistical data from World Bank official site. It is the first reconstruction of the long-term agriculture dynamics of Ukraine on the base of filtered correlated data sets of 1996-2018. The main advantages of this research are the revealed turning points in Ukraine agriculture development that can be used by other researchers in investigation of economy and economic history.

Practical value / implications. To raise precision of analysis and avoid wrong interpretation of outcomes it should be taken into consideration all factors that impact on events and thus it is rational to verify data and clean them from random oscillations especially studying long-term tendencies in the development of such systems as economy branches or country entire. Moreover, it helps to reveal peaks of growth and recession points in business activity and make more coherent predictions on the future development. The article presented the effectiveness of filter methods applying and results of analysis that can be used in management and forecast of long-term development in Ukraine agriculture. Such methodic can be applied to the analysis of both individual industries and the economy as a whole.

Key words: smoothing data set, model, tendency, fluctuations, correlation. 


\section{Agricultural and Resource Economics: International Scientific E-Journal}

http://are-journal.com

Introduction and review of literature. The agriculture in Ukraine is a strategic producer and provider of raw and food for people in our country, it is a source for export abroad and consequently is one of the most important branches in the Ukraine economy. Agriculture is the branch that the most influenced by the seasonal and cyclical factors. These factors may slightly change main tendency but cannot turn it into opposite direction decisively. Anyway, some investigations do not take into consideration noticed fact and build models on the base of raw data that always include several layers of impact results including not only periodic but also random fluctuations. Because of this in reconstructed dynamics latent or unrevealed events stay overlooked or omitted. Some Ukraine researchers studied different sides in agriculture development in mentioned way. For example, investigating agriculture branch of Ukraine for the last 15 years explorers took into consideration such factors as yield, the average tractor engine power in agricultural farms, the average wage of employee in this branch and built an econometric model characterizing the dependence of production on mentioned factors in the form of linear multidimensional model [1]. Researchers assumed that built linear equation may have multicollinearity. Although, the fact is that any development of complex economic system can be described by the linear regression only approximately, because any development can change its direction from up to down and vice versa especially in agriculture production that depends on nature, seasonal and cyclical factors. Thus, miss of certain turning points could lead to the lacunas in economic history.

The long-term tendencies can be reconstructed with wavelet analysis as it was proved by G. Nigatu and M. Adjemian [2] based on fluctuations in prices of corn, soybeans, cotton on the agriculture markets in USA, Brazil, China, India. They argumented the fact that the wavelet applying helps study periodic oscillations in data series. Moreover, they built portrait of price changes that took place through the long period of time and revealed structural fluctuations and the break points in price relationship. As it was asserted by researchers, the conventional methods cannot be applicable in long-term tendency analysis. Saying about wavelet approach it is the way to smooth data and exclude indirect fluctuations or shortly it is way to clean data sets. V. Krishnamurthy, E. Leoff, J. Sass [3] simulated and analyzed oscillations or volatility in economic returns with filter applying in Markov models. M. Leippold and $\mathrm{H}$. Yang [4] investigated peculiarity of the mixed-frequency particle filter for non-linear dynamics in volatility of bonds and dollar index returns. Using MarkovChain Monte Carlo approach they concluded that short period among data is better for prediction based on smoothed data sets. R. L. Czudaj [5] studied volatility of agricultural futures trading volume, interest rates, time-varying impulse responses for markets of coffee, corn, cotton. It was used Markov Chain Monte Carlo algorithm to find shocks in volatility of indicators and causes of its.

Some authors compared effectiveness of contract farming as a form of vertical integration of agricultural sector that existed in West Africa [6], but they did not take into consideration the long-term tendency in development. Long-term dynamics in agriculture growth has studied by M. I. Ayuda and V. Pinilla [7]. Researchers 
investigated the structure and trends of Spanish agricultural exports, shares, and its contribution in economy development. They revealed factors that impacted in Spain on the growth of whole economy. T. Baležentis and A. Oude Lansink [8] studied a dynamic productivity of Lithuanian grain and oilseed farms. M. Hachula and $M$. Rieth analyzed the impact of financial investors on price formation in agricultural futures markets [9]. As it is seen, scientists raise mainly problems related to the peculiarities in dynamic data sets and the factors that impact on agriculture, form volatility in prices of securities and fluctuations of indicators in agribusiness activity or productivity.

To use for analysis correct data is the way to reveal real factors and their impact on consequences in development. The measurement of bias between the real and model data that was gained by the linear regression and production functions were presented by Kibrom A. Abay. [10]. As it was claimed after conducted research, the quality of collected data influences on the quality reconstruction of theoretical models of economy development. A. Ford Ramsey studied how weather impacts on yield distribution with Bayesian spatial quantile regression method. He proved that yield modelers should consider spatially varying effects in their investigations of agriculture development. He recommended for it to use appropriate statistical models [11]. The necessity to use nonlinear methods in long-term data sets analysis of agriculture development was shown in issue by other explorers [12].

The example and interesting part of scientific heritage in the field of information deep analysis can be found in the economic research of development dynamics. The results were presented in reconstructed cycles in business activity and numerous attempts to predict crises. Moreover, some economists tried to prove existence of memory in long-term processes in economy systems as in alive organisms despite their complexity and origin [13]. Considerably, existence of long-term memory can be revealed in humanity activity and in all its aspects from economy processes to society historical memory, and thus the problem of genuine information remains actual in related areas. Previous events influence on future. To get pure information is important, because it helps to make theoretical model of development and predict it outcomes. The global task of other explorations was to reveal and understand main trends in dynamics without incidental factors that can slightly break but not strongly change the main tendency of direction $[14 ; 15]$.

Mentioned question of relevant data is important due to the necessity to predict and avoid crisis periods or make them not such disastering. Contemporary Ukrainian researchers try to study experiences of foreign country strategies that base on the analysis of long-term tendencies in development [16; 17]. The quality information problem is studied by representatives of other sciences that suggested an analytical background on the main ideas and approaches in information field theory [18].

The elimination from data sets random oscillations is suggested to be made by various methods. For all reasons, the smoothing methods and filter approaches are the most applicable in investigation of the long-term trends. The smoothing with moving averages causes data set shortening by the size of the period that is the data averaging 
range. As proved by researchers such shortening leads to the loss of information about boundary events of the process and hence to the wrong conclusion about whole behavior of economic system. The Holt-Winters method bases on the exponential smoothing with investigation of the cyclical and seasonal components that change direction of curve. Method helps to make forecast, but the precision of it is too sensitive to the previous fluctuations and as many other methods it theoretical model includes considerable deviation from real trends [19]. The filtration method by Hodrick-Prescott provides separation of input data sets on the several functions and each of them is suitable to reconstruct processes on different levels of determination without loss of information [20, p. 2-5]. One of the functions is the trend or the most structural and determined component that is modelled by the constant factors. The second one describes seasonal and cyclical fluctuations shaped by periodical impacts. Lastly, the function of random fluctuations that formed usually due to the events that are stochastic and unpredictable [14].

The purpose of the article. The purpose of the paper is to study agriculture development in independent Ukraine using methods for decomposition of data sets to obtain structural components according to their level of determination and to investigate main tendencies without random fluctuation.

Results and discussion. This research was held on the base of statistical data from World Bank official site [21] and covered the period of 1996-2018 in development of agriculture, forestry, and fisheries in Ukraine. Studied indicators are food export fraction in GDP, added value created by agriculture, forestry, and fisheries (in USD in current course) and it share in GDP, official exchange rate of national currency (UAH per USD), average added value per one agrarian employee (in USD), agriculture raw partition in production export. To decompose data series into components by the Hodrick-Prescott method and to construct scatter plots, scripts were created for the purpose of calculations and their visualization by means of GNU Octave. This article presents differences between behavior patterns of development in Ukrainian agriculture for the period of 1996-2018 in case of uncleaned data and data without random fluctuations. The next stage in our investigation with comparing correlated data dynamics helped to reveal turning points in agriculture trends.

Suppose that rise of agriculture added value correlates with increase of percentage of food exports in GDP. It means that the more significant development of agriculture in comparison with other branches of economy, the more fraction of food production export and vice versa. At first sight these both indicators can be related through the linear regression and this fact is illustrated by scatterplot in the Fig. 1.

Form of scattering points area foresees linear model that approximately describes dependence of food export fraction on added value amount created by agriculture, forestry, and fish economy. Moreover, verification by Fisher and Student criteria makes it possible not to reject the hypothesis of model adequacy and the significance of the coefficient of the regression equation at $x$. However, the insignificance of the free coefficient of the regression equation suggests that the 
influence of other factors that are not considered in the model should be excluded and leave the determined structural components that formed the general dynamics of the agriculture.

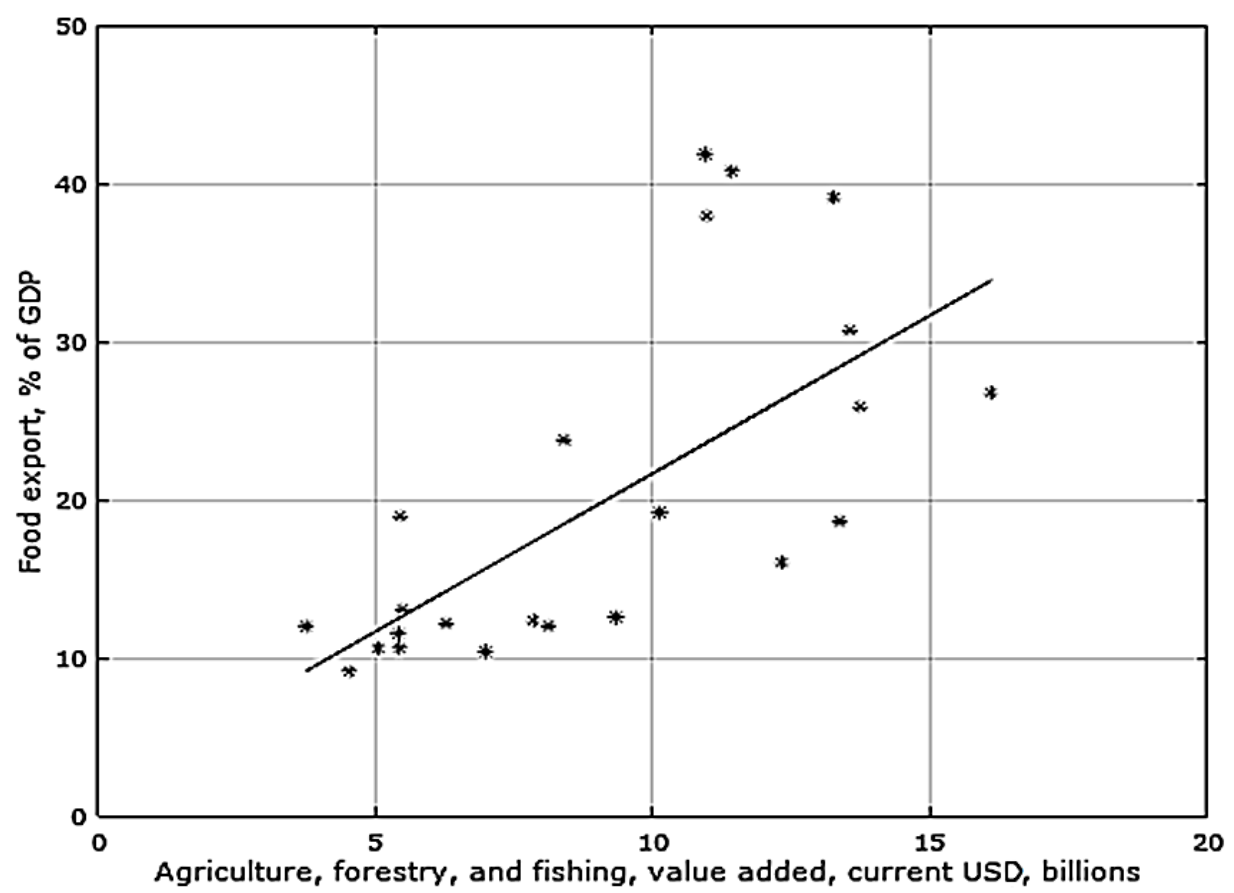

Fig. 1. Changes in the percentage of food exports depending on the value added created by agriculture, forestry, and fisheries (USD, at current exchange rates)

Source: calculated and built by the authors based on data [21].

It was shown by E. Peters [13] that time series can be characterized not only by autocorrelation of residues, but also by the memory of past control processes, and it is expressed in the corresponding reaction to the deterministic influence. The direction and elongation of the correlation cloud, the concentration of points on the two indicators plane reflects the effect from systemic, deterministic influence. Considerable residual variance means the existence of other influences, which to a lesser extent but still form a trend of the process. Nowadays econometrics allows successfully approximate theoretical models to the real data, however, built trends may not reveal all development peculiarities in economy. For example, looking at the Fig. 1 we cannot say for sure which moments of agricultural development were the most decisive, and when the growth line changed significantly or turned into the opposite direction. Simultaneously, correlation cloud allows to assume the positive relation between features but not to reconstruct dynamics of process in whole.

To see how portrait of indicators behavior can be clarified and thus to make more coherent conclusion, we conducted analysis, which results are given below. To reveal turning points, where systemic factors affected on investigated variables, data sets should be cleaned from random and cyclical fluctuations with Hodrick-Prescott method for data smoothing [14, p. 3]. This method was tested by V. Dmytriieva in research of tendencies in dynamics of crop production in Ukraine for the period 1990-2017 [22], where it was concluded about necessity of correct data collection, verification, and cleaning. 
Shortly, R. Hodrick and E. Prescott [14] offered to decompose data set $Y_{t}$ on several components $\left(G_{t}-\right.$ structural, $C_{t}-$ cyclical and $\varepsilon_{t}-$ deviation in measurement accuracy):

$$
Y_{t}=G_{t}+C_{t}+\varepsilon_{t}
$$

Using the criteria of least squares:

$$
\sum_{t=1}^{T} C_{t}^{2}+\lambda \sum_{t=2}^{T}\left[\left(G_{t+1}-G_{t}\right)-\left(G_{t}-G_{t-1}\right)\right]^{2} \rightarrow \min ,
$$

structural component can be found theoretically according to the formula:

$$
G_{t}^{*}=A \cdot Y_{t} \text {. }
$$

In this equation $A$ is a covariation matrix:

$$
A=\left(I_{T}+\lambda K^{T} K\right)^{-1},
$$

where:

- $K$ - the matrix of $(T-2) \times T-$ dimension and it consists of second differences of data set;

- $K^{T}$ - the transposed matrix $K$;

- $I_{T}$ - the matrix unit of $T \times T$-dimension;

- $T$ - the length of the time series;

$-\lambda$ - the smoothing parameter that can be picked up according to the period of time series (for example, $\lambda=14400$ for annual data, $\lambda=100$ for month data, $\lambda=1600$ for quarterly data) [20, p. 3-6].

Determined components of dynamics data sets of value added created by agriculture, forestry, and fisheries (in USD) and food export fraction from GDP of Ukraine are in the Fig. 2 with solid smooth line, real data are shown with points, and, finally, broken line of other fluctuations is located underneath both graphs.

The correlation cloud without random fluctuations is presented in the Fig. 3. As it was calculated, the correlation in uncleaned data equals to 0,68 , and correlation based on smoothed data sets is 0,83 . Here the direction of development is sketched by the solid line with arrow. Thus, it is possible to reveal three different processes with three main turning points (they are undersigned and shown with arrows):

- synchronic decline from 1996 to 1999 of both dynamics,

- simultaneous growth after 1999 up to 2013,

- lowering in value added (USD, at current exchange rate) and at one time sharp rise of food export percentage after 2013 up to 2018.

The first period is explained with systemic decline in Ukraine economy that led to the cutback in the amount of agricultural production and it export. The second one demonstrates the rise of business activity that was observed in all spheres of economy including agriculture.

The third period is interesting with it opposite directions in development, when in conditions of a slight decrease in the amount of value added (agriculture, forestry, and fisheries product) the share of food exports had continued to grow. 

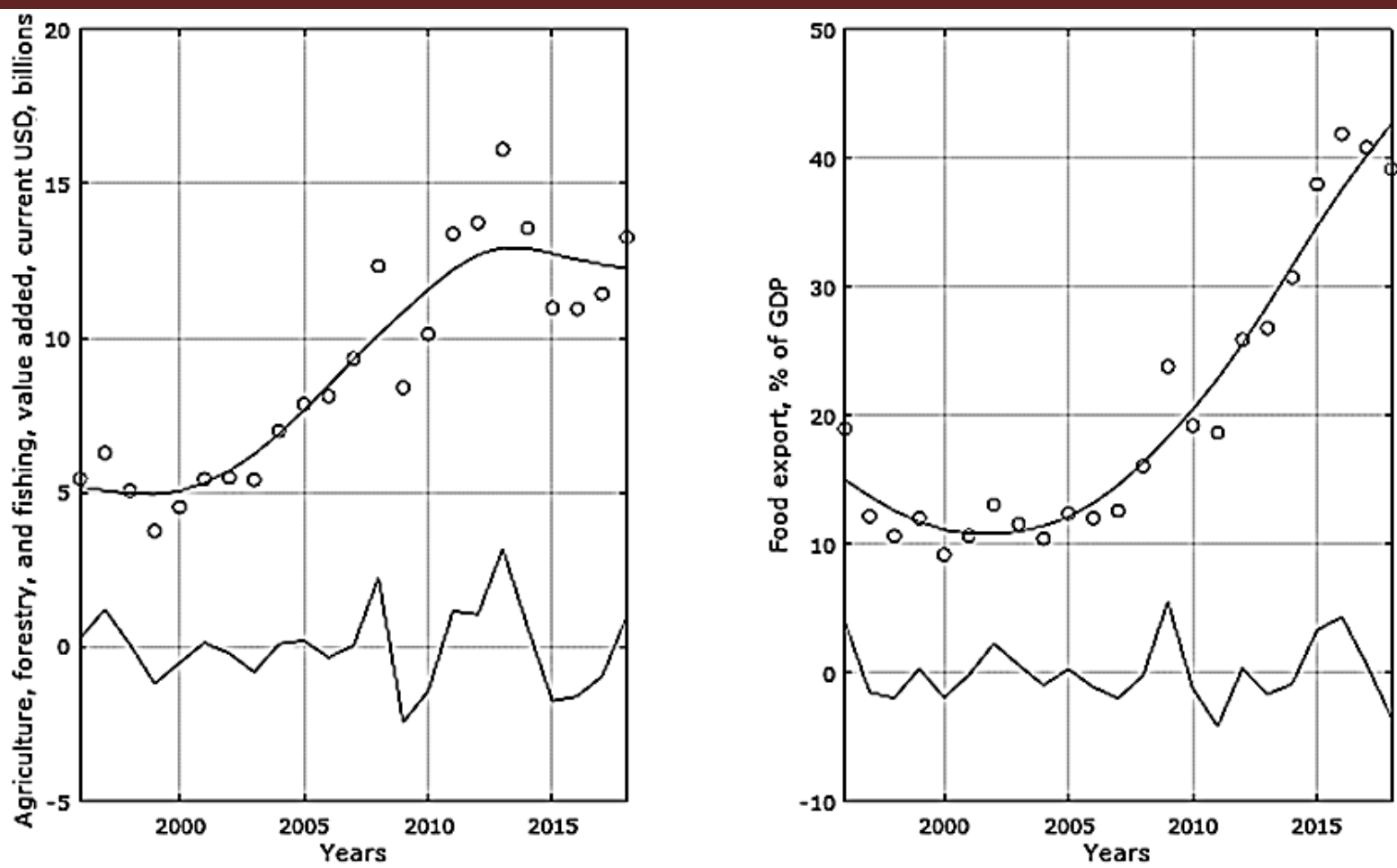

Fig. 2. Trends in value added created by agriculture, forestry, and fisheries in USD at exchange rate (left) and the percentage of food exports in total GDP (right)

Source: calculated and built by the authors based on data [21].

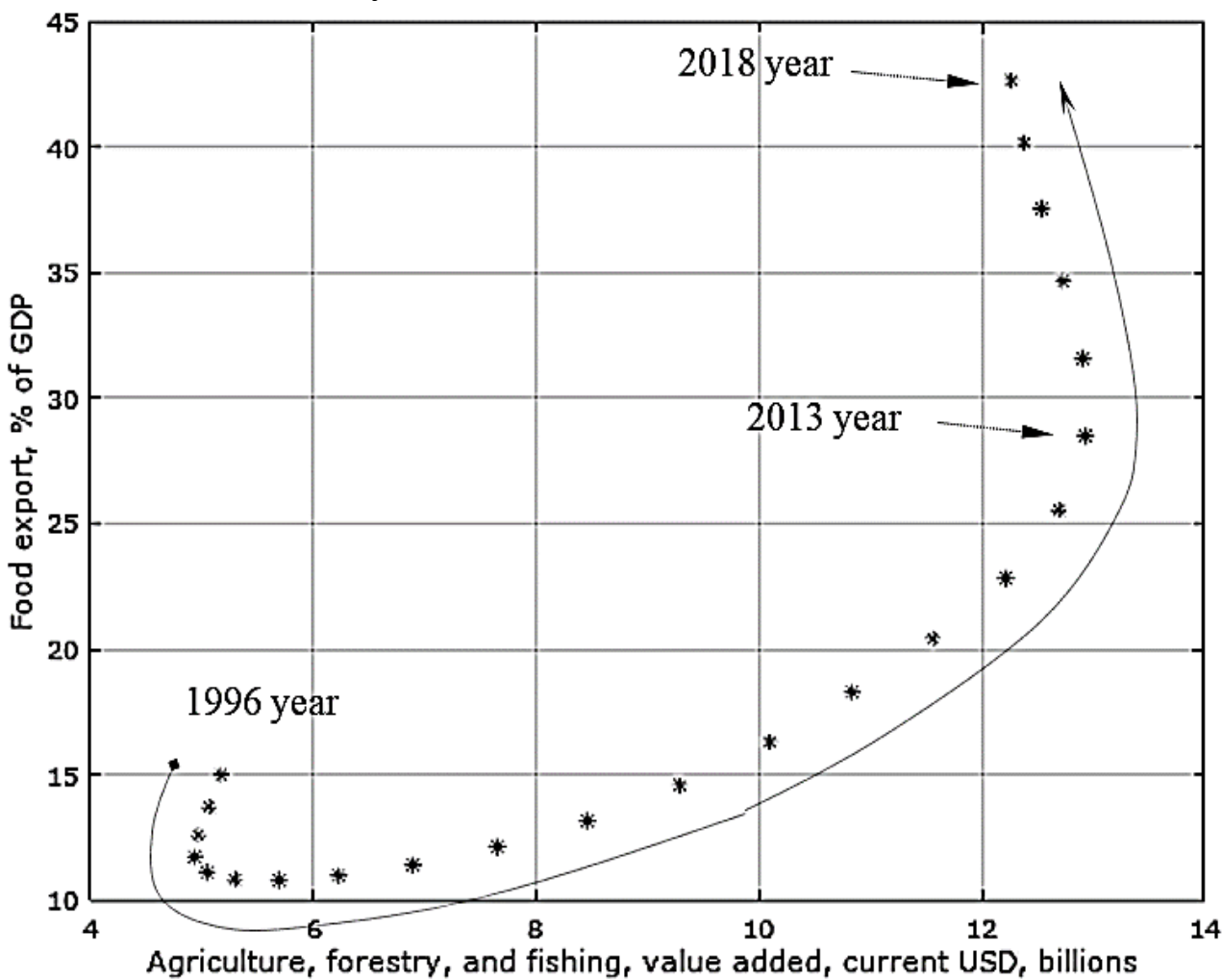

Fig. 3. Correlation cloud built on purified data on the food export share in GDP dependent on value added in agriculture, forestry, and fisheries (in USD, at exchange rate)

Source: calculated and built by the authors based on data [21]. 
Described tendency provoked two questions to investigate. The first, was decline of value added caused by decrease of branch productivity? And the second, could instability in the national currency value relative to the USD call cutback of value added and lead to the rise of food export fraction in GDP? Therefore, we investigated dynamics of official currency rate and value added per worker (Fig. 4).

Since 2014 dynamics of the UAH rate against the USD has changed due to the National Bank of Ukraine provided mechanisms for the currency value formation on the market. Government has rejected strategy of fixed rate of national currency and, consequently, it affected on economy. At the beginning the inflation jumped up for the short period, but then correct regulation of bank and finance system helped stabilize economic development and stimulate business activity in our country despite foreign expansion. At the same time, rise of hryvnia value has impacted on the cost of products and services. Thus, it is assumed that foreign currency value increase partly could have led to the fast growth of the value added created by agriculture.
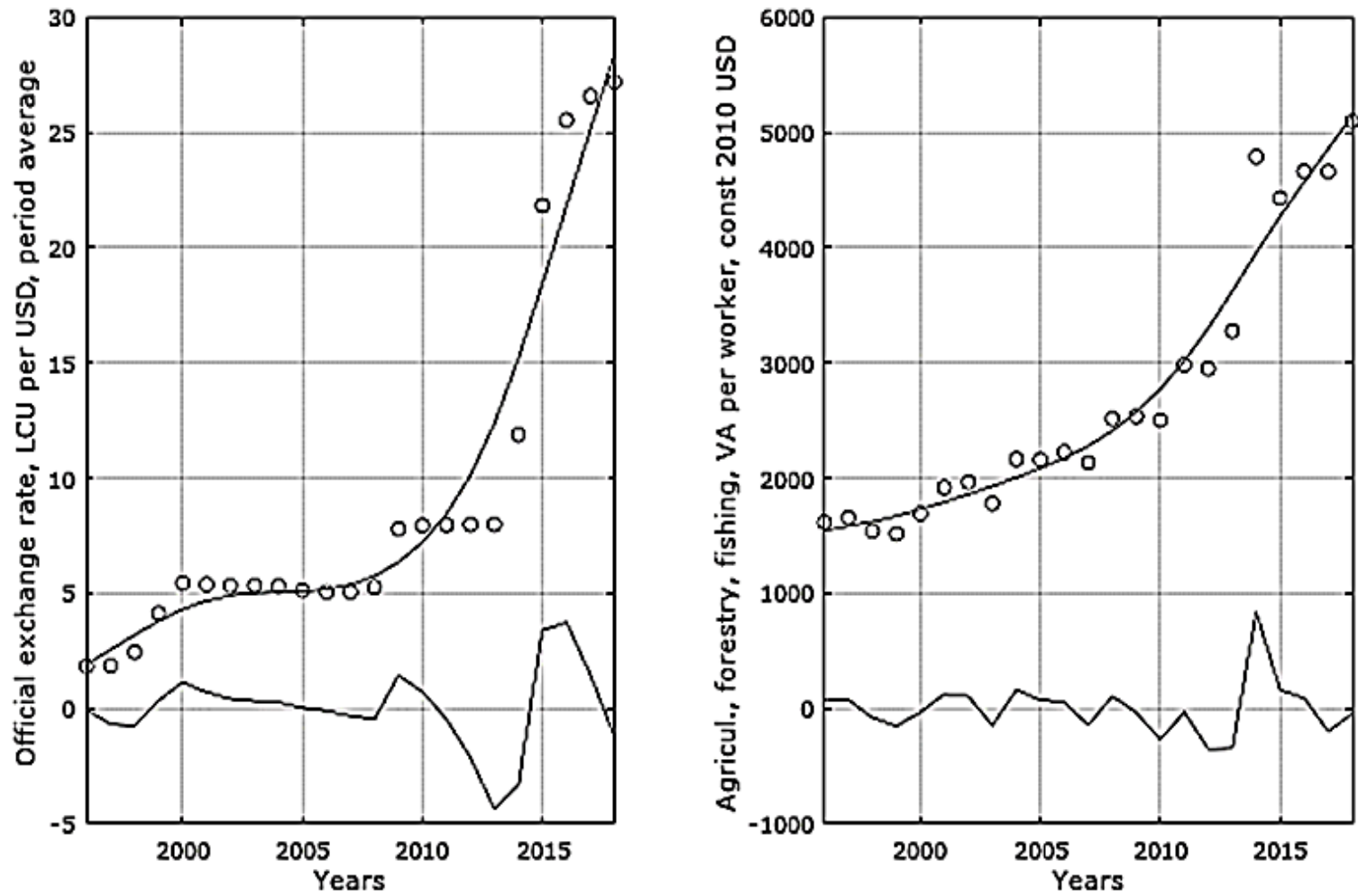

Fig. 4. Trends in the official exchange rate of the UAH against the USD (left) and value added per agricultural worker (right)

Source: calculated and built by the authors based on data [21].

The solid line with arrow in the Fig. 5 of scattering points presents sharp upgrowth of the agricultural product price, that was created by one employee, synchronically to rise of the foreign exchange rate. This tendency is observed at the right-side graph of correlation of deterministic components during the period 2009-2018 (the correlation here is 0,97 contrary to 0,91 of its value calculated on the basis of unfiltered data). It does not mean that amount of product has become bigger, but it is obvious that the product created by one employee began to be valued at an amount in currency equivalent many times larger than it was in 1996-2008. Can this trend be considered as a 
negative phenomenon in the development of agricultural and related industries?

To answer the one question, it was made attempt to understand another. What was the tendency of agriculture, forestry, and fisheries development in fractions of value added in GDP and export of food as an outcome of its production? The dynamic components free of random fluctuations show asynchronous tendencies in the Fig. 6. At the period as fraction of food export (in the right) was going up from 2007 and gained the highest point of rise in the 2018, the fraction of value added created by agriculture and related industries (in the left) had started growing only after 2010 and to 2018 year had not yet equaled to the fixed amount of 2000 year.
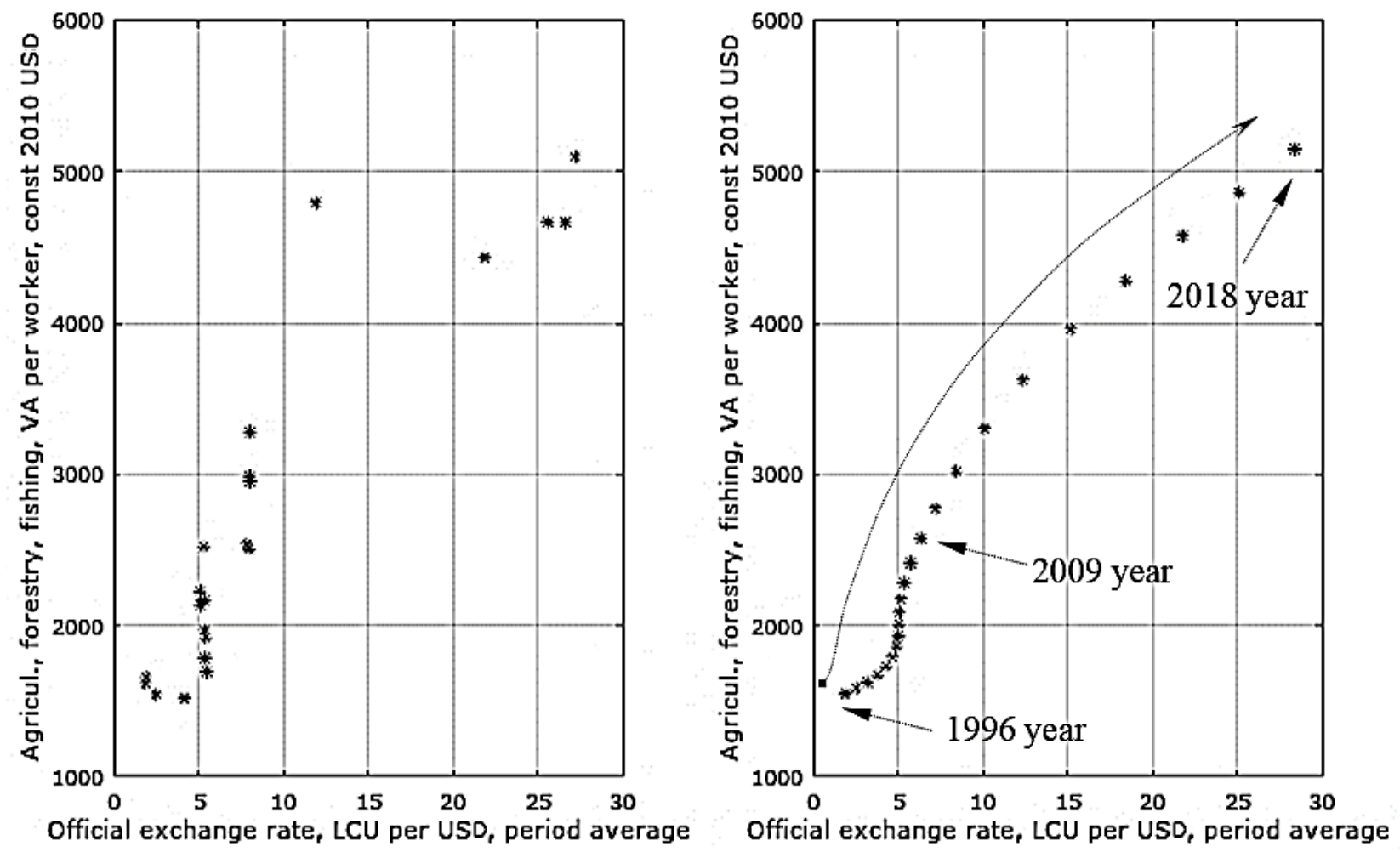

Fig. 5. Dynamics of change in the cost of employee labor in agriculture depending on the growth of the value of foreign currency

Source: calculated and built by the authors based on data [21].

Supposed that production of agriculture had started to be estimated in higher price even staying on the level of percentage in GDP that was lower than its value of 2000 year. Such a revaluation was made possible by the intentions of Ukraine agriculture to meet the requirements of international markets, which manifested itself in improving product quality. Points cloud in the Fig. 7 (left) built on the real data does not allow describe tendency firmly, its correlation form is undefined.

Whereas data filtering helped to determine structural components and reveal trend (Fig. 7, right) with crucial turning points in it (the arrows show direction and turning points signed in the graph). It is noticed the existance of the opposite directions that have different values of correlation: the first is $-0,83$ and the second is 0,99 based on the filtered data (against $-0,58$ and 0,87 based on the unfiltered data). The trajectory on the right shows that since 1999 the share of value added of agriculture, forestry and fisheries in the country's GDP had been declining, while the 
share of food exports had remained virtually unchanged and was quite low until 2009. It is noticed that direction has changed qualitatively after 2009 and turned into the growth of the agriculture production fraction in Ukraine economy simultaneously with considerable rise of income from food export.
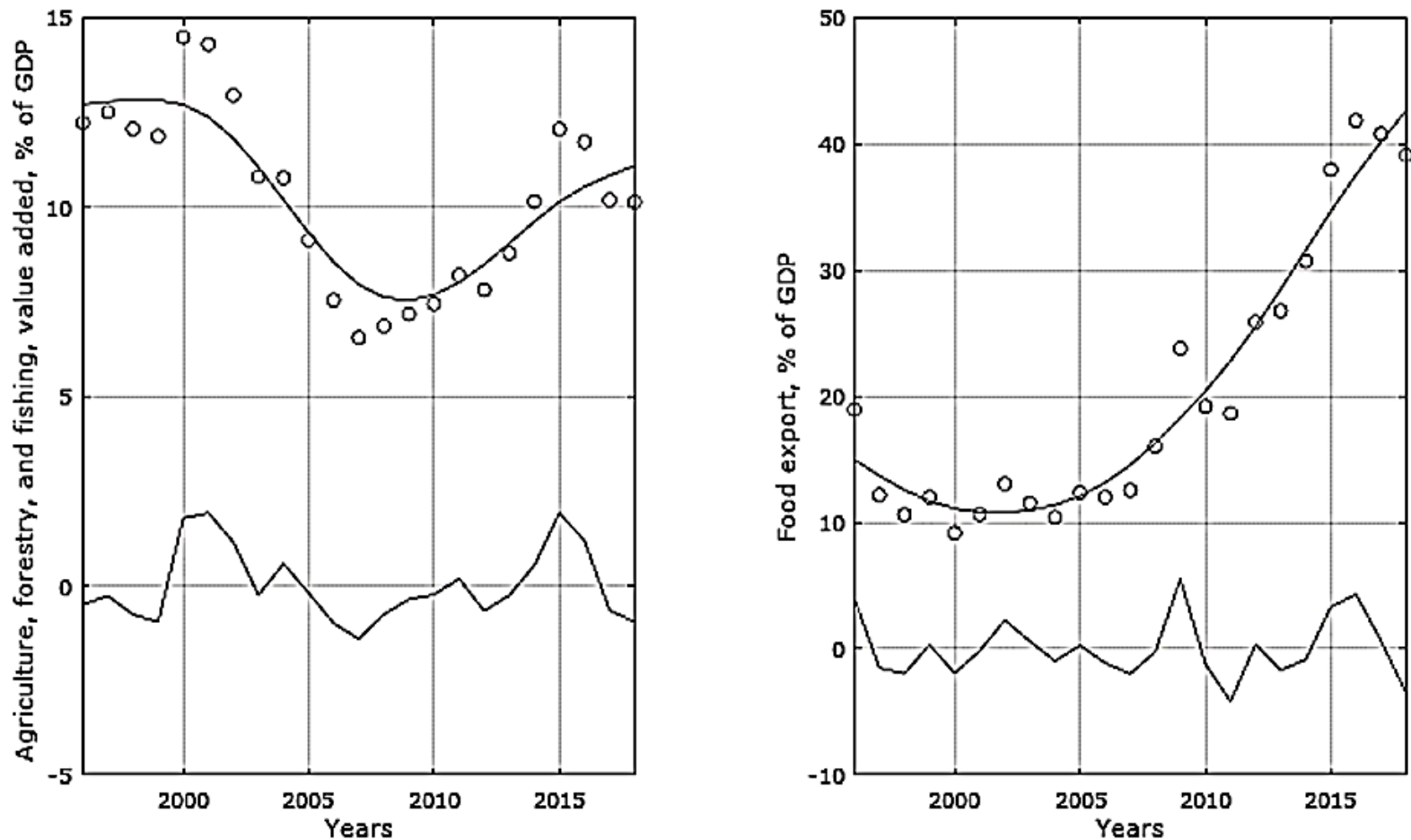

Fig. 6. Trends in the share of GDP of agriculture (left) and food exports (right)

Source: calculated and built by the authors based on data [21].
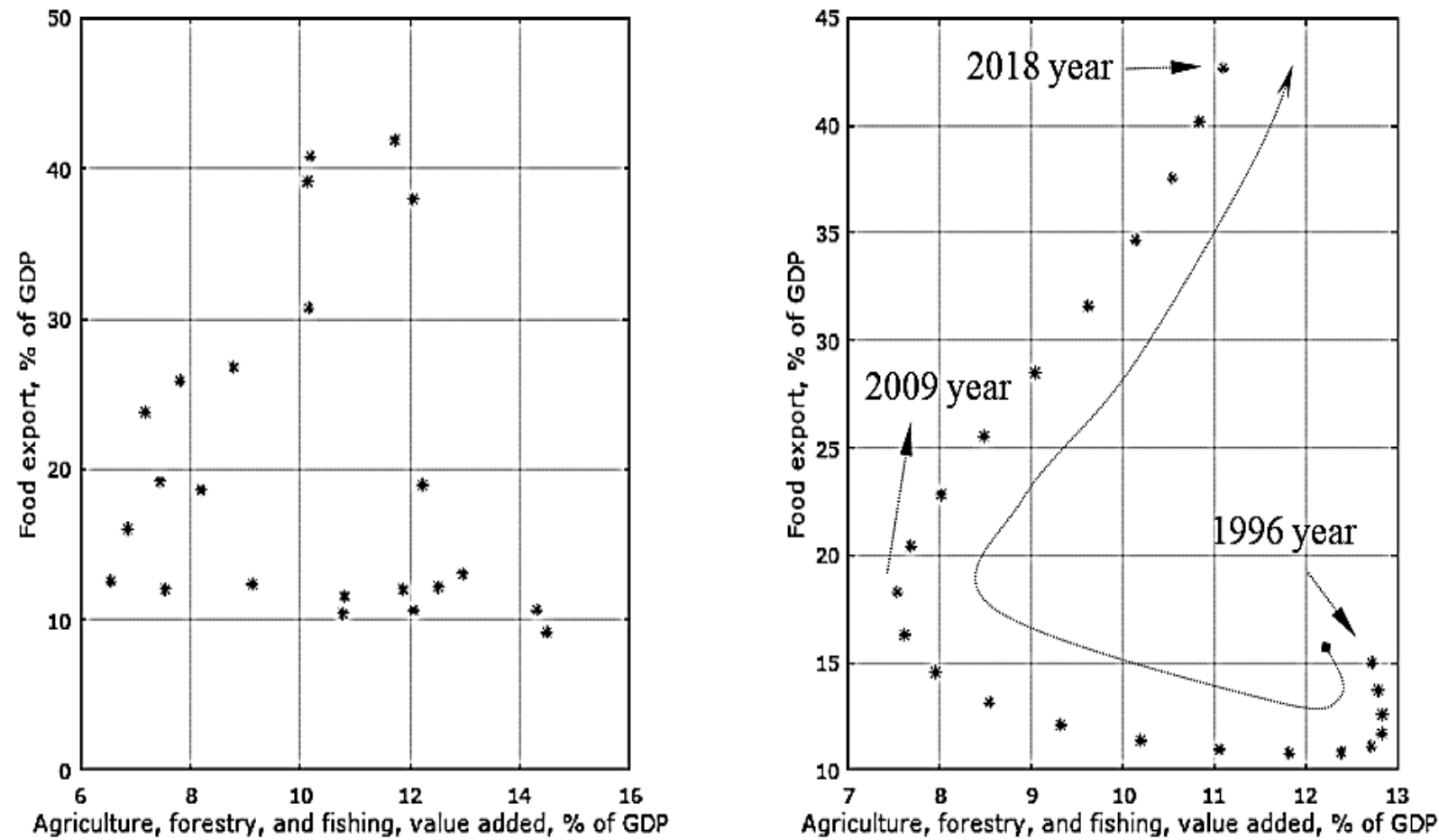

Fig. 7. Correlation dynamics of shares in GDP of food exports and value added created by agriculture, forestry, and fisheries (real and filtered data sets)

Source: calculated and built by the authors based on data [21]. 
Importantly that made above conclusion is confirmed by the dynamics of change in the share of the studied industry in GDP from the average productivity of the employee worked in it (Fig. 8, right). From 1996 to 2009 decrease of agriculture value added percent of GDP was occurred on the background of practically unchanged productivity of branch. Qualitative turn took place in indicators dynamics after 2009 (it is pictured in the graph with arrows) and it is seen clear that the more product had being created by agriculture employee the bigger share of it was becoming in GDP. This fact means that increase of agriculture part was accompanied with likely shortening of other branch productivity shares.
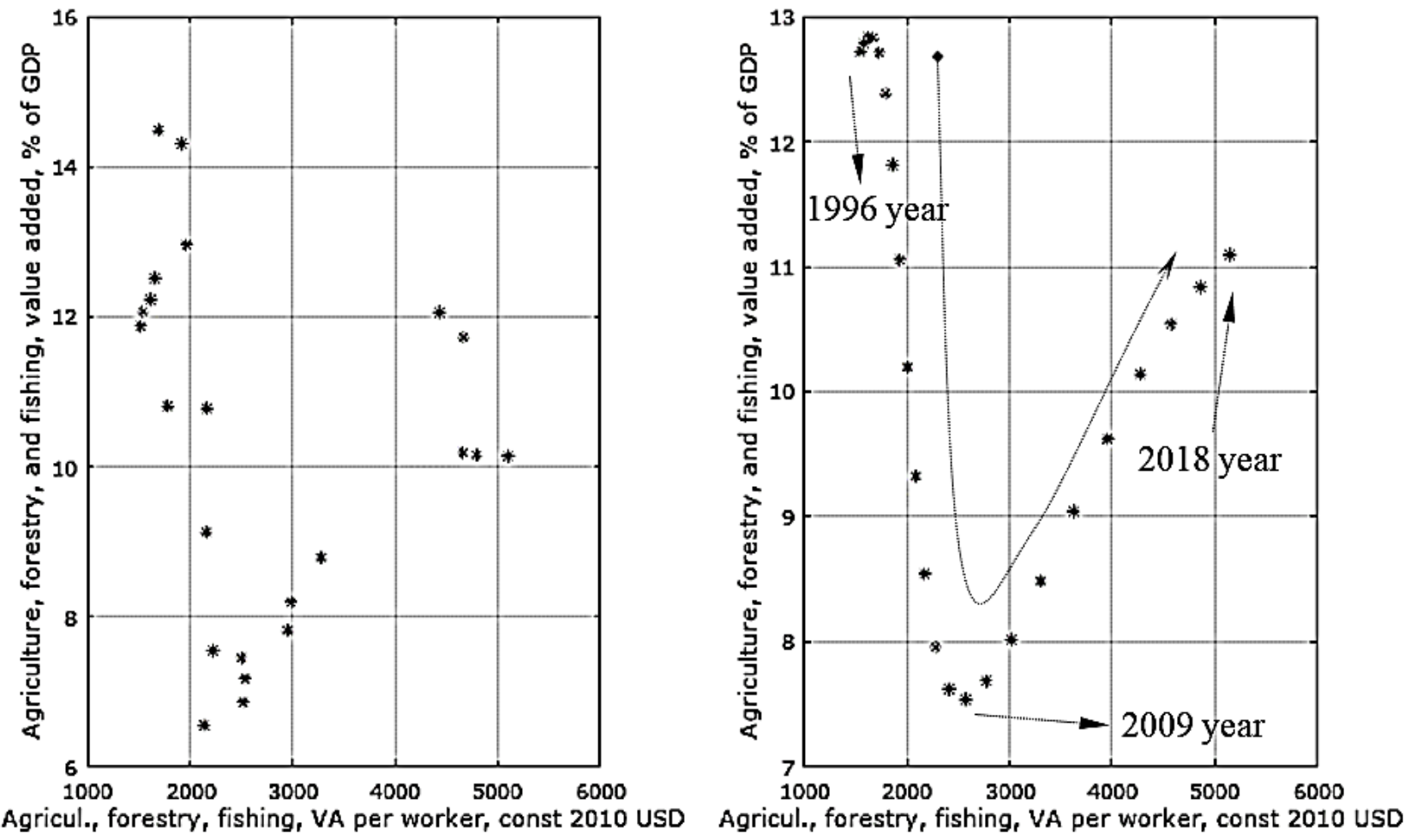

Fig. 8. Dynamics of agriculture value added part in GDP in correlation with productivity of agriculture employee

Source: calculated and built by the authors based on data [21].

As it was in the previous described Fig. 7, the dynamics of two directions in the Fig. 8 improved after data filtering. The correlation of the first direction is $-0,97$ (against -0,77) and the second is 0,99 (against 0,84 based on the unfiltered data).

Agribusiness is the raw provider as for internal participants of economy activity, as for external subjects of economic process. Thus, it is matter to study how fraction of raw selling has changed in total export. The trend of raw materials export is described by the wavy line that is identical to the tendency behavior of share of value added created by agriculture, forestry, and fisheries (Fig. 9). It could be assumed that being researched indicators should present strong positive correlation, because the more product is made by the branch, the more it may be sold abroad.

As it could be seen, the fraction of raw export was inconsiderable in GDP and after going down to $0.8 \%$ in 2008 it went up to $2 \%$ only in 2018 year. The share of value added was on the bottom level of $6.8 \%$ in 2008, but after that it has risen 
higher than $10 \%$. It can be considered that agriculture tried to sell more raw materials than it was earlier. Was the described dynamics so unambiguous? As it can be noticed in both graphs, the 2015' stress peak took place in Ukraine (presented in broken lines) that was caused by foreign aggression and thus splash of instability in economy. Were there any consequences of that stress for the agriculture?
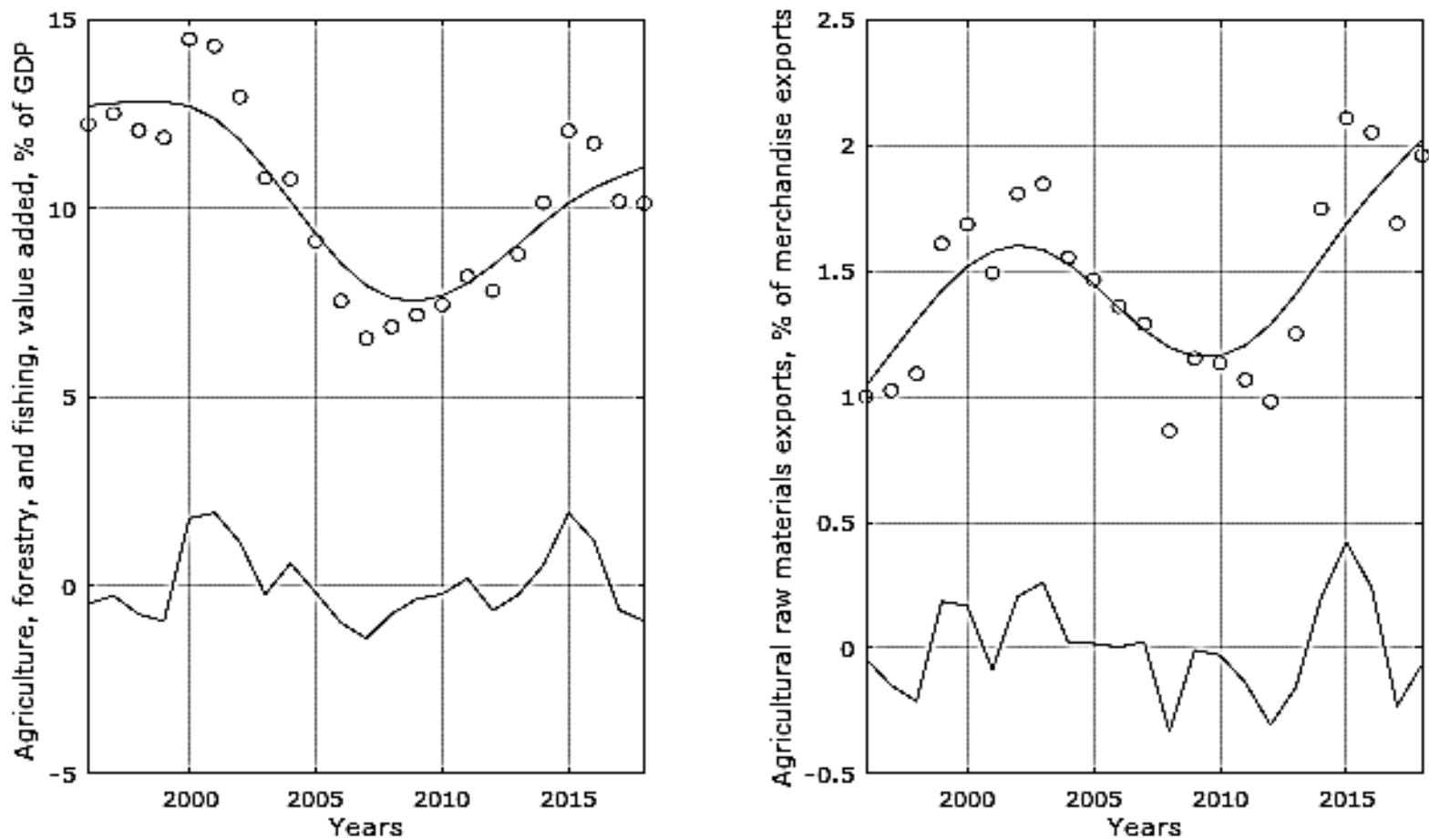

Fig. 9. Dynamics of the shares of raw export and value added created by agriculture and related industries

Source: calculated and built by the authors based on data [21].

To answer the questions, the correlation of both dynamics was analyzed by authors. Fig. 10 (left) presents scattering of points without firmly determined dynamics. The increasing trend could be approximated to this scatter, but filtering processes helped reveal the several opposite tendencies in the dynamics. Analysis of filtered data are shown in the right graph by the solid line with arrow leads to the conclusion that in sales abroad the fraction of raw export was increasing from 1996 to 2000, while part of agriculture value added was staying unchanged in GDP.

As it can be seemed, the branch potential has been spent up to the 2000 year and the process of agriculture production has started to reduce simultaneously with decline of raw export. For the weak economy unexpected powerful factor would be disastrous. The financial crisis happened in 2008-2009 has impacted all the world economy. The evidence of it can be found in various investigations described as countries suffered from the consequences. The decline in long-term dynamics that happened due to the financial crisis was typical not only for Ukraine but for foreign countries too [23].

Nevertheless, the several years regress in Ukraine agrarian sector finished in 2009 and the industry began to revive. Such tendency is confirmed by the behavior of all reconstructed dynamics as a conclusion of conducted analysis. Therefore, the 2009 
year can be fixed as a notable turning point in the agriculture development.
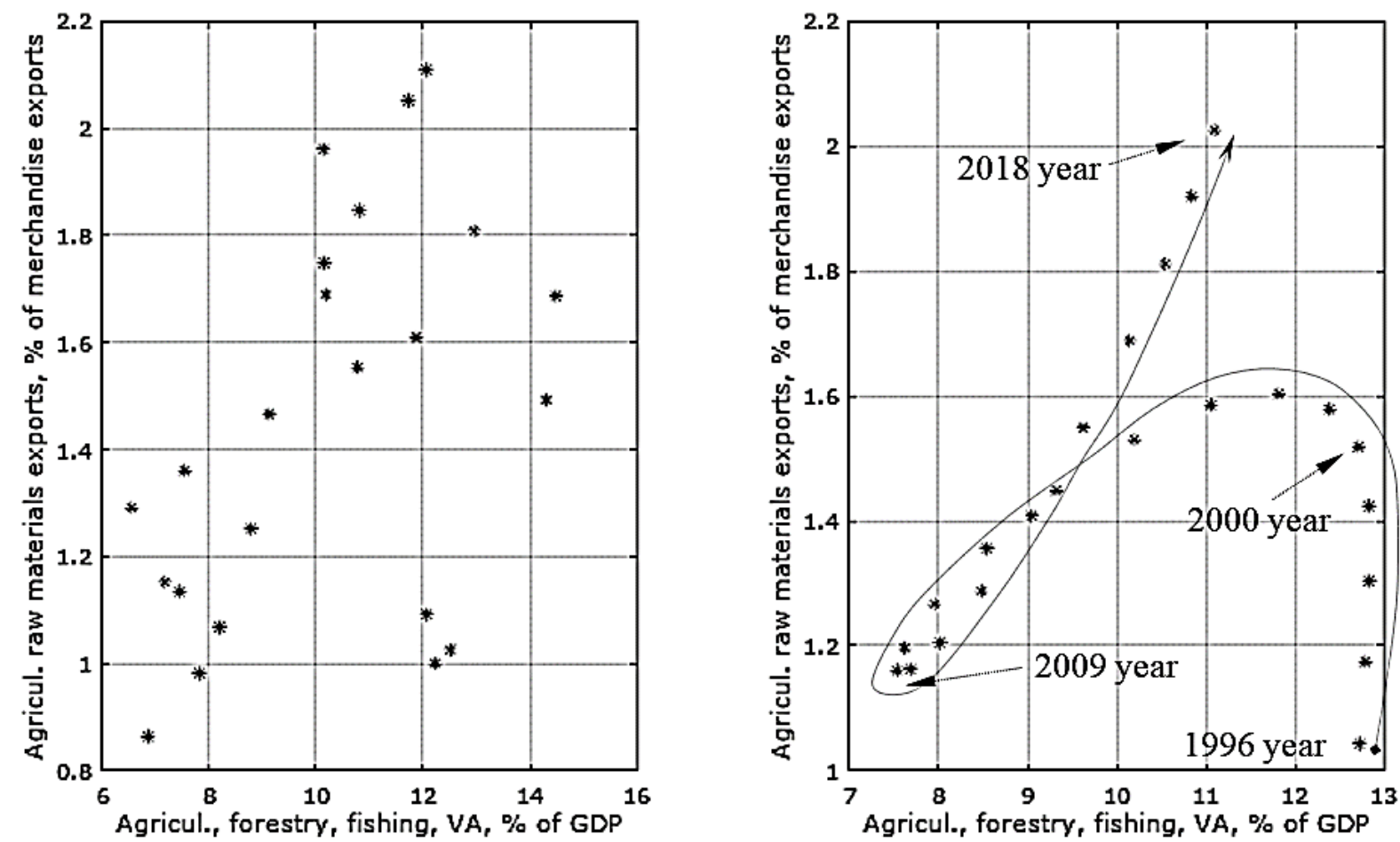

Fig. 10. Correlation dynamics of the shares of raw export and value added created by agriculture and related industries

Source: calculated and built by the authors based on data [21].

What caused the revive of agriculture economy? The Verkhovna Rada of Ukraine adopted the Law "On State Support of Agriculture of Ukraine" in 2004 [24]. Another Law "On Amendments to Certain Laws of Ukraine on Improving the Mechanisms of State Regulation of the Agricultural Market" was approved in 2009 [25]. The laws were provided for insurance of agricultural products and support the national production through the State intervention fund established by the Agrarian Fund. The main task of it was commodity and financial interventions to support prices stability. The law defined certain types of agricultural products (goods) as objects of state price regulation. Besides, government made decision to do constantly monitoring of agrarian market, lending, investing, and subsidizing of agricultural enterprises. Thus, our state acted as a regulator and insurer in case of adverse events. It is worth to notice that due to it support the agriculture economy in Ukraine started to hold to the European standards of production quality that allowed country to expand step by step own export abroad despite the financial crisis of 2008-2009.

Site "AgroPortal" has presented statistics according to which in 2018 year 4,2 billion UAH was invested in agriculture including $57 \%$ for support livestock branch and $22 \%$ for purchases of agricultural machinery. In 2019 the budget has been expanded on $40 \%$ in comparing with sum of previous year and the amount of expenditure for livestock support was increased in 1,5 times [26]. Described above tendencies proved that decisions made in time by government had motivating effect on agriculture development. Moreover, as it was asserted by S. Gutkevych, the state support gave investors reason to contribute to Ukraine agriculture development [27, 


\section{Agricultural and Resource Economics: International Scientific E-Journal}

http://are-journal.com

p. 53]. The fraction of agriculture branch increased to the level of almost $40 \%$ in 2018 from $24 \%$ in 2009 as the World Bank statistics evidenced [21]. Besides that, since 2009 the average amount of agriculture production per one employee has appraised higher. Value added per worker in 2009 was 2537.8 USD and in 2018 it become already 5099.3 USD. Simultaneously, the shares of other industries had cut down. That means that agriculture in Ukraine improved own position among other branches. As a provement, the agriculture value added fraction in GDP in 2009 was $7.2 \%$, but in 2018 it reached the level of $10.1 \%$. The food export percentage in merchandise exports of our country has risen despite the impact of the World financial crisis on the Ukraine economy.

It is supposed that part of positive result was caused by impact of rational management. Even taking into consideration the rapid fluctuations in the value of foreign currency and decline of hryvnia value, that happened in all industries and kinds of business activities, the agriculture started changing in Ukraine GDP structure thanks to augmentation of own part of income and productivity.

Conclusions. This article presents the effectiveness of use methods that can help clean data from random fluctuations and raise quality of analysis of time series. As it presented in the paper, the correlation method applied in analysis of real data sets allows to assume existence and to establish type of dependence in tendencies of two indicators. However, to reveal in development of branches or entire country economy turning points, where these systems crucially have been changing the direction of their trends, it does matter to apply methods for data sets filtration, to exclude random oscillations and, thus, to obtain structural components with clear dynamics. Such approaches help more firmly represent development of the branch and explain behavior of other related characteristics. The Hodrick-Prescott-method was used here to decompose without information loss the input data sets into several functions according to their levels of determination and stability of influence on trends formation.

As it was calculated, the quality of analysis based on the filtered data was increased up to 10 percent in average. As a result of conducted research, at least two periods in agriculture development during the 1996-2018 were discerned. It was found out that each of them is characterised by its own direction. The first is from 1996 to 2008 had features of decline and stagnation, thus the agriculture, forestry, and fisheries value added (\% of GDP) slimed in 1.7 times. The second is from 2009 up to 2018 has demonstrated enlargement of mentioned indicator in 1.4 times. As the analysis shows, the branch productivity has increased in twice since 2009. It was clarified that 2009 year has became the main turning point where development of agriculture in Ukraine changed trends into positive direction. The revealing of these stages became possible due to studying the correlated dynamics of filtered data sets.

In perspective, the use of filtering approach for data cleaning before the indicator's dynamics modelling can help to build more precise predictions of their behavior on the base of purified data. It is supposed to apply such methods to forecast decline or growth in development of Ukraine economy. Analyzing agriculture 
development, it is necessary to take into consideration specific of the branch, it seasonal character, dependence on nature and weather changes, made decisions for financial and material support, economical conjuncture and other factors that form trend of the branch. It is anticipated to be used all overmentioned in further studies of the dynamics in order to identify large and medium cycles in the development of the agricultural sector, which could help to identify peaks and periods of recession in business activity in this area.

\section{References}

1. Samarets, N. and Nuzhna, S. (2019), Formation of agrarian component of ukrainian commodity exports. Economics. Ecology. Socium, vol. 3, pp. 34-47. https://doi.org/10.31520/2616-7107/2019.3.1-4.

2. Nigatu, G. and Adjemian, M. (2020), A wavelet analysis of price integration in major agricultural markets. Journal of Agricultural and Applied Economics, vol. 52(1), pp. 117-134. https://doi.org/10.1017/aae.2019.35.

3. Krishnamurthy, V., Leoff, E., and Sass, J. (2018), Filterbased stochastic volatility in continuous-time hidden Markov models. Econometrics and Statistics, vol. 6, pp. 1-21. https://doi.org/10.1016/j.ecosta.2016.10.007.

4. Leippold, M. and Yang, H. (2019), Particle filtering, learning, and smoothing for mixed-frequency state-space models. Econometrics and Statistics, vol. 12, pp. 2541. https://doi.org/10.1016/j.ecosta.2019.07.001.

5. Czudaj, R. L. (2019), Dynamics between trading volume, volatility, and open interest in agricultural futures markets: a Bayesian time-varying coefficient approach. Econometrics and Statistics. vol. 12, pp. 78-145. https://doi.org/10.1016/j.ecosta.2019.05.002.

6. Codjo, O. S, Acclassato, D., Fiamohe, R., Kpenavoun, S, and Biaou, G. (2020), Comparative analysis of the preference of producers and processors for domestic rice production contracts in Benin. Agribusiness, vol. 36, pp. 242-258. https://doi.org/10.1002/agr.21618.

7. Ayuda, M. I. and Pinilla, V. (2020), Agricultural exports and economic development in Spain during the first wave of globalisation. Scandinavian Economic History Review, pp. 1-18. https://doi.org/10.1080/03585522.2020.1786450.

8. Baležentis, T. and Lansink, A. O. (2019), Measuring dynamic biased technical change in Lithuanian cereal farms. Agribusiness, vol. 36, is. 2, pp. 208-225. https://doi.org/10.1002/agr.21623.

9. Hachula, M. and Rieth, M. (2020), Estimating the Impact of Financial Investments on Agricultural Futures Prices using Changes in Volatility. American Journal of Agricultural Economics, vol. 102, issue 3, pp. 759-785. https://doi.org/10.1093/ajae/aaz024.

10. Abay, K. A. (2020), Measurement errors in agricultural data and their implicationson marginal returns to modern agricultural inputs. Agricultural Economics, vol. 51, pp. 323-341. https://doi.org/10.1111/agec.12557.

11. Ramsey, A. F. (2019), Probability distributions of crop yields: a bayesian spatial quantile regression approach. American Journal of Agricultural Economics, 
vol. 102, is. 1, pp. 220-239. https://doi.org/10.1093/ajae/aaz029.

12. Sotoudeh, M. A. and Worthington, A. C. (2017), Nonlinear effects of oil prices on consumer prices: a comparative study of net oil consuming and producing countries. Review of Economic Analysis, vol. 9, pp. 57-79.

13. Peters, E. E. (2004), Fractal market analysis: applying Chaos theory to investment and economics (Internet-trading Trans.), Internet-trading, Moscow, Russia. (Oraginal work published 2003).

14. Hodrick, R. J. and Prescott, E. C. (1997), Postwar U.S. business cycles: an empirical investigation. Journal of Money, Credit and Banking, vol. 29, no. 1, pp. 116.

15. Bekaert, G., Hodrick, R. J. and Kiguel, A. (2019), Variance risk in global markets. SSRN Columbia Business School Research Paper Forthcoming. https://doi.org/10.2139/ssrn.3442649.

16. Reznikova, O. O., Voitovsky, K. E. and Lepikhov, A. V. (2020), Natsional'ni systemy otsinyuvannya ryzykiv i zahroz: krashchi svitovi praktyky, novi mozhlyvosti dlya Ukrayiny [National systems of risk and threat assessment: best world practices, new opportunities for Ukraine], NISS, Kyiv, Ukraine.

17. Tyshchenko, L. and Chaibok, A. (2017), Financial Stress Index for Ukraine. Bulletin of the National Bank of Ukraine, vol. 240, pp. 5-14.

18. Sviatets, Yu. A. (2017), Information field of historical research. Dnipropetrovsk University bulletin. History \& archaeology series, vol. 25(1), pp. 29 42. https://doi.org/10.15421/261703.

19. Kobets, S. and Luzina, A. (2019), Application of adaptive models for forecasting a net sales. Efektyvna ekonomika, vol.4, available at: http://www.economy.nayka.com.ua/?op=1\&z=6991.

20. Polasek, W. (2011), The Hodrick-Prescott (HP) filter as a bayesian regression model. Economics Series (277). Institute for Advanced Studies, Vienna, Austria.

21. The World Bank (2020), Ukraine. World Development Indicators, available at: http://api.worldbank.org/v2/en/country/UKR?downloadformat=excel.

22. Dmytriieva, V. A. (2018), Tendencies in Ukrainian dynamics of crop production: effects of data sets smoothing. Efektyvna ekonomika, vol. 12. https://doi.org/10.32702/2307-2105-2018.12.87.

23. Davydenko, N. and Pasichnyk, Y. (2017), Features of socio-economic development of the Baltic States and Ukraine. Baltic Journal of Economic Studies, vol. 3, no. 5, pp. 97-102. https://doi.org/10.30525/2256-0742/2017-3-5-97-102.

24. The Verkhovna Rada of Ukraine (2004), The Law of Ukraine "On state support of agriculture of Ukraine", available at: https://zakon.rada.gov.ua/laws/show/1877-15.

25. The Verkhovna Rada of Ukraine (2009), The Law of Ukraine "On amendments to certain laws of Ukraine concerning the improvement of mechanisms for state regulation of the market of agricultural products", available at: https://zakon.rada.gov.ua/laws/show/1447-17. 
26. AgroPortal (2019), Infographics. The first agricultural results of the year in infographics, available at: https://agroportal.ua/ua/publishing/infografika/pervyeagrarnye-itogi-goda-v-infografike.

27. Gutkevych, S. (2019), Investment attractiveness of industries: features and trends. Baltic Journal of Economic Studies, vol. 5, no. 3, pp. 50-58. https://doi.org/10.30525/2256-0742/2019-5-3-50-58.

\section{Citation:}

Стиль - ДСТУ:

Dmytriieva V., Sviatets Yu. Turning points in agriculture development in Ukraine: results of analysis on the base of purified data. Agricultural and Resource Economics. 2021.

Vol. 7.

No. 1.

Pp. 5-21. https://doi.org/10.51599/are.2021.07.01.01.

Style-APA:

Dmytriieva, V. and Sviatets, Yu. (2021), Turning points in agriculture development in Ukraine: results of analysis on the base of purified data. Agricultural and Resource Economics, vol. 7, no. 1 , pp. 5-21. https://doi.org/10.51599/are.2021.07.01.01. 